\title{
Helping the Next 4 Billion Go Online Part I: Design Research for Digital Literacy Education
}

\author{
Victor Udoewa \\ Instructional Designer, Education \\ Lead, Deputy Director of $18 \mathrm{~F}$ \\ Learn \\ Washington, DC 20006 \\ victor.udoewa@gsa.gov \\ Lokesh Bhog \\ Technology Specialist \\ NIIT \\ Gurgaon, Haryana, India \\ lokeshbhog@gmail.com
}

\section{Bhawana Prabhakar \\ Project Engineer, Developer \\ Ericsson, Wipro Technologies \\ Mayapuri, New Delhi, India \\ bhawanaprabhakar@gmail.com}

\author{
Neil Mathew \\ Graduate \\ Amity University \\ Uttar Pradesh, India \\ mathew.neil@gmail.com
}

\section{Anuranjan Gupta \\ Student \\ NIIT}

New Delhi 110087, India

anuranjannet@gmail.com

\author{
Saummya Kaushik \\ Postgraduate Student \\ University of Auckland, \\ Takapuna New Zealand \\ kaushiksaummya@gmail.com
}

\author{
Louie Al-Hafidh \\ Customer Service Supervisor \\ Google Fiber \\ Charlotte, NC \\ louiea@google.com
}

Valentina Humar

Director of Innovation and Business Dev.

GJ Comunicaciones

Bogotá - Colombia

vhumar@gjcomunicaciones.com

Abstract - In 2015, over two hundred million people, around the world, went online for the first time bringing the number of people worldwide using the Internet to 3.2 billion. Still, a majority of the world, about 4.2 billion, is offline. The barriers to going online and becoming digitally literate can be greater than just infrastructural obstacles, including psychosocial barriers related to incentives, affordability, and user capability. Our goal is to help the next 4 billion go online by designing an educational solution to equip people with digital literacy skills to improve their lives. We have employed a human-centered design methodology through community research, synthesis, ideation, and prototyping to build solutions first for northern and central India. The design may be re-contextualized in order to scale to new locations. This paper focuses on the research and synthesis phases of our design process during which we first define digital literacy relevant to the local context and then conducted fieldwork to collect stories, observations and quotes from numerous communities with varying levels of digital literacy. That feedback was translated into insights, themes, and frameworks that will later inform the design and development of an educational technology intervention.

Index Terms - Digital literacy, Educational curricula, Human-centered design, India 


\section{INTRODUCTION}

In today's knowledge economy, it is possible to find older information in physical libraries. But with so much new information available online, and some of it only online, it is increasingly important to have access to online information in order to fully participate in this economy and benefit from its knowledge. This idea is supported by various studies indicating a high correlation between a country's Internet access or use and a country's gross national income (GNI) per capita or $\mathrm{GDP}^{1-7}$. It is for this reason that one area of international and community development is development of information and communication technologies (ICTs). One obvious barrier to ICT is the lack of physical infrastructure ${ }^{8}$. This includes subterranean fiberoptic networks as well as maritime, seafloor cables connecting various continents and coastal points. Additionally, this includes infrastructure related to mobile phone networks like cell phone towers.

But even with a mobile network or an underground fiber-optic network, an often forgotten, large part of physical access is device access ${ }^{8}$. Today a majority of the world accesses the Internet through a mobile device ${ }^{9}$. This includes people who have never accessed the Internet through a laptop or desktop computer. They are using tablets, smartphones (Tier-1 phones with full Internet capability) and feature phones (Tier-2 phones with limited Internet capability). Today, with large decreases in the retail price of smartphones, illustrated by Mozilla's shortlived, \$33 smartphone first launched in India in 2014, Internet-capable mobile phones are providing more and more people access to the Internet for the first time ${ }^{10}$.

In 2013, 243 million people came online for the first time, primarily through mobile phones $^{11}$. In 2014, over 250 million people came online bringing the number of people using the

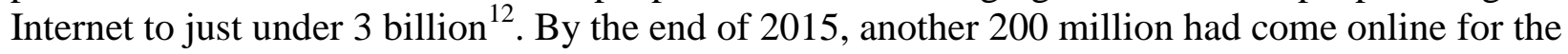
first time bringing the total number of people online to 3.2 billion, over $40 \%$ of the world's population $^{1,13}$. However, the majority of the world is still offline - about 4.2 billion people - and still not enjoying the correlated benefits of the Internet and of participating in a wider knowledge economy $^{1,14}$.

An important concept to note is the definition of "online" used here from the International Telecommunications Union (ITU) ${ }^{15}$. It is defined as having "accessed the Internet at least once in the past 12 months from any kind of device." This means that not everyone considered "offline," lacks physical, infrastructural access. For example, imagine an elderly person in a rich country whose neighborhood has Internet access but who has never started using the Internet. So the 4.3 billion offline people-group includes people with physical, infrastructural access. On the other hand, not everyone counted as "online" is truly online. Imagine, a young woman from a rural area in sub-Saharan Africa who traveled to the medium-sized town once last year and borrowed someone's mobile phone for 15 minutes playing with Facebook for the first and only time last year. In a similar manner, the almost 3 billion online people-group includes people who are not habitually "online" and definitely includes people who use it but are not sufficiently digitally literate.

These two examples and corresponding limitations of the ITU's measurement imply two things. First, digital literacy education is needed and helpful for portions of the almost 3 billion online people. In other words, being online does not imply being digitally literate. Secondly, and most importantly, as the example of an offline, elderly person in a rich country demonstrates, 
lack of physical, infrastructural access is not the only barrier to being online and becoming digitally literate. In broad terms, barriers to going online can be grouped into four broad categories (Table 1$)^{8}$.

TABLE I

Barriers to GoIng OnLINE

\begin{tabular}{|l|l|}
\hline Incentives & Affordability \\
\hline $\begin{array}{l}\text { Lack of time } \\
\text { Irrelevance } \\
\text { Lack of awareness } \\
\text { Lack of socio-cultural acceptance } \\
\text { Fear }\end{array}$ & High price \\
\hline User Capability & \\
\hline $\begin{array}{l}\text { Lack of ability with digital tools } \\
\text { Lack of English literacy } \\
\text { Lack of dominant language literacy } \\
\text { Difficulty of using/learning the Internet }\end{array}$ & $\begin{array}{l}\text { Infrastructure } \\
\text { Lack of fiber-optic network } \\
\text { Lack of device access }\end{array}$ \\
\hline
\end{tabular}

Educational outreach initiatives, which focus on digital literacy education, can directly or indirectly address all categories of barriers. An example is a mobile Internet bus with educational classes and games. It provides device access, mobile Internet coverage, consistent power and free access for people from low-income neighborhoods while increasing awareness and competency, teaching relevance and how to create relevant content, and affecting acceptance while decreasing fear. Some educational outreach initiatives focus on one barrier or category of barriers, like a radio or TV awareness campaign and some, like a mobile bus, focus on multiple barriers at the same time. Ultimately, the aim of our company's ICT educational outreach initiatives is digital literacy and digital inclusion for those who are offline.

Our company, a large multi-national Internet technology (IT) corporation, has natural incentives to increase digital inclusion and increase the number of people who are digitally literate worldwide. When there are more people who are digitally literate, then there will be more people who can access and will use our tools. Also, our company wants people who come online for the first time to use our products rather than a competitor's products. The drawbacks of this motivation is that our digital literacy work is largely focused on our digital literacy tools rather than being tool-agnostic. The benefits of doing this work with the support of our large multinational corporation is access to sufficient funding for the work and access to a wide network of collaborators on both international and local levels. Fortunately, our company's profit motivations, though different, are aligned with the altruistic motivations of employees who completed this work as a side project, not a highly prioritized project within our organization. Moreover, our organization did not affect the approaches used. The first author is the only instructional designer in the organization using the approach used in this paper, so our approach is unorthodox and not well supported within instructional design community in our company. 
However, our team felt our approach was best for the research questions we are working to solve in the area of digital literacy.

\section{Contextualizing Digital Literacy}

It is not enough to simply be online in order to benefit from the knowledge therein; one must also become digitally literate to navigate, find, and take full advantage of this online knowledge. In order to assess whether a person is digitally literate or not or what percentage of a country is digitally literate, we must first define digital literacy. Currently there is no one definition of digital literacy around the world. This makes sense in light of the fact that in different countries and contexts people need to be able to do different things in life, with or without digital tools. So the relevance and importance and even use of digital tools changes in different spaces and places.

To give an example, one of the authors advises the Tinder Foundation in collaboration with the UK government in an effort to make $100 \%$ of UK adults, aged 16 and higher, digitally literate by the year $2020^{16}$. In order to assess whether that goal is met, they had to define digital literacy in a UK context. Let us follow an example of how one criterion for UK digital literacy was designed ${ }^{17}$.

1. First, being a rich country, most of those who are not digitally literate in the UK fall in two major, non-exclusive categories: the low-income and the elderly.

2. Second, many people in low-income situations in the UK are looking for jobs or want better jobs.

3. Third, most of the jobs in an Internet-friendly country like the UK are online.

4. Therefore, one criterion for digital literacy in the UK is "must be able to find jobs online." Other criteria are defined similarly.

It is this relevant, contextual defining of digital literacy that is much more important than general, context-blind definitions of digital literacy. What should people in this context be able to do if they are digitally literate? That is the question we must answer if we want to assess digital literacy and readiness. Previously, in our company's global digital literacy initiatives, this assessment work was wanting. As a result, we have received a number of criticisms on the Web Academy curriculum, Online Basics ${ }^{18}$. Some found it too long; others found it too short; some, too difficult, others, too easy. It highlighted a problem of context, audience, and targeting. Instead of a general module on "How to Search" or a "Search Engine," we want to be able to have a contextualized module like "Find Jobs Online." Both teach similar skills but one is embedded in the problems and complexities of the lives of people, making it much more relevant.

In this work, our goal was to start over and redesign an educational solution to digital illiteracy in six steps.

1. Choose a local context.

2. Define digital literacy in that context.

3. Define design research questions to pursue.

4. Choose a research methodology.

5. Perform designed-based research.

6. Design and test prototypes of solutions. 
We would then use that solution as a master solution or a standard solution that would be recontextualized as we repeat the process in a different geography for a different people-group.

\section{Choose a local context}

In our professional work, we focus on developing countries with a burgeoning middle class and a booming GDP--emerging market countries. The growing middle class makes these economies quite conducive for outside or foreign investments which help increase the countries' GDP. However, the emerging market countries also tend to be countries with growing inequality creating a stratified social economy ${ }^{19-24}$. In such situations, foreign investment that increases overall GDP can simultaneously have the effect of increasing the economic inequality gap. In this research, we attempt to do work that contributes to GDP and GNI in ways that decrease and ultimately eliminate the gap, by focusing on lower-income populations where digital illiteracy is high. Because of our professional work in emerging market countries, we have many contacts in through Latin America, sub-Saharan Africa, the Middle East, and Asia. Due to India's massive population and booming economy, our company does the most, emerging markets work and tests the most emerging markets products in India. Furthermore, a majority of the global offline population are located in China and India ${ }^{1}$. Therefore, India was chosen.

Additionally, one of the authors has undergraduate students he has previously taught in short courses in Delhi, India. These students and other contacts provided a community from which team members could be recruited. Therefore Delhi was chosen as the central location for our work, spreading out to rural areas around there.

\section{Define digital literacy}

Before discovering a contextualized definition of digital literacy, we needed a general definition to provide the bounds within which we could contextualize. However, there is no one definition of digital literacy ${ }^{25-27}$. We decomposed the problem, first defining "digital." Then defining literacy based on all skills a student learns in a language course in school, we generally defined digital literacy using 6 components.

1. Effectively search and navigate through large amounts of digital information.

2. Efficiently find specific digital information.

3. Efficaciously understand and analyze digital information.

4. Accurately evaluate digital information.

5. Appropriately communicate digital information to another person or groups of people.

6. Effectively create digital information.

We realize that digital literacy is not a binary state of competency, but more accurately represented by a spectrum of increasing ability. However, our goal is to define a contextualized and locally useful, minimum standard of digital literacy for north and central India that we can use to update our curriculum. 


\section{Define design research questions to pursue}

To couch our curriculum within the context of the lives of the community members, we had one major research question to answer.

1. What are the problems, issues, difficulties, and complexities community members face on a daily basis, as well as their hopes, fears, and ambitions?

The answer to this question would greatly affect the content of our design, or at least the context of the content.

But we still needed to design the delivery of the content as well, leading to our second major research question to answer.

2. What is the best method and style of delivery of digital literacy education for maximum educational impact for the north and central Indian communities?

\section{Methodology}

The most important factor in determining which research methodology to use is the research question $^{28}$. Because our first research question is open-ended, lacks a specific hypothesis, and seeks to uncover the beliefs, hopes, fears, problems, and difficulties in the life of the community members, a qualitative research methodology is best.

However, the answers to the questions will be used in an initial design. Since both questions are used to design the content (question 1) and delivery (question 2) of an educational technology intervention used to increase digital literacy, we also need a design experiment or design-based research methodology. Design-based research (DBR) is characterized by pragmatism (solving current, real world problems), theory (producing learning theories based on research and testing of designs), iterations (using an iterative design process), integration (integrating multiple research methods), and contextualization (local design for local communities) $)^{28-30}$.

Because DBR often is initiated by the educational researchers as opposed to practitioners and may never be implemented in an actual learning environment, we employ a more narrow version of DBR called Design-based Implementation Research. Design-based Implementation Research (DBIR) has 4 guiding principles. These include jointly negotiated work (this work was initiated and requested by learning communities teaching the Web Academy curriculum), iterative and collaborative design processes (our design team includes community members), development of theories (theories guide and emerge from our design research and work), and design for viability (sustainability and capacity building) $)^{31-37}$.

Design-based Research, in general, does not have to use a mixed methodology, though sometimes it does. In this case, we are combining DBIR with a qualitative methodology; therefore we chose the mixed methodology called Human-centered design (HCD, user-centered design, or design thinking) as our overarching framework because it combines a qualitative methodology with $\mathrm{DBIR}^{38-41}$. In education, HCD is often called student-centered design or learner-centered design (LCD). Human-centered design is only a methodology, not a solution. It can be used to design a building, a project, software, a process, a service, a product, an environment, a program, an organization, or even a curriculum. Human-centered design mixes skills from engineering design such as defining the problem, setting the constraints, and rapid prototyping with practices from the social sciences such as ethnographic studies, interviews, 
extracting insights from qualitative data, and empathic immersion ${ }^{42-45}$. In short, human-centered design keeps the design work centered on the users, the beneficiaries, or the community. In this work, HCD creates two pillars. First, instead of the traditional model where the designers go away, design a solution, and then bring it back to the community, in $\mathrm{HCD}$, we practice coparticipatory design where the community is involved in every stage of the design process ${ }^{46-48}$. Second, instead of the design team only including members from outside the community, the design team also includes community members.

In this work, the design team includes 7 local Indians from the greater Delhi area. Second, we involved not only local design team members but also local community members in every stage of the work.

Human-centered design is normally broken into three stages, Discover, Design, and Deliver. The first stage (Discover) is a research stage where you listen and learn from the community, developing empathy and connecting yourself to the needs and desires of the community. The second stage (Design) is a stage of data analysis and synthesis of previous qualitative work, then ideation, prototyping, and iteration. The final stage (Deliver) is the stage of pilot planning, developing a feedback loop, defining success, partnerships, and developing business models for financial viability and sustainability.

The remainder of the paper is broken into two remaining main sections. First we provide a brief overview of the procedures and methods used in the first half of the HCD process (Discover and first half of the Design stage). Then we provide the results of the synthesis process: themes, insights, frameworks, and learning theories. All of this will inform the ideation and prototype process to be presented in a future paper.

\section{LEARNING THEORIES}

In DBIR, learning theories both guide and emerge from the research and design. Such learning theories do not refer to overarching theories such as constructionism or experiential learning, but rather smaller learning theories dealing with the specific context of the educational intervention ${ }^{49}$. If we had an established learning hypothesis we wanted to test, a quantitative research methodology may have been more appropriate ${ }^{28}$. In this case, however, the design team debated over three main learning questions.

First, is digital literacy education necessary, or can people learn on their own? Our company division lead repeatedly argues that his U.S. children learned to use phones and tablets simply by playing with them; they had no instruction. The rest of the world can learn the same way, according to him. On the other hand, other design team members say that many of us grew up with the technology so the learning curve for staying up to date is less steep than the learning curve for someone starting with no knowledge and learning how to use a mobile app.

Second, the head of our division believes that a Massive Open Online Course (MOOC) could be used to scale digital literacy education around the world. Design team members disagree saying that MOOCs are not accessible to the digitally illiterate.

Third, are mastery and retention higher when digital literacy education is all online through connected devices or through an offline classroom time followed by an online lab time? Our team was also divided on this question. 
Fourth, some team members felt one global solution could work for all, while others felt we needed various local solutions.

The most important learning theory that divided our team was the connection between reading and writing literacy and digital literacy. Half of the team believed literacy is a prerequisite for digital literacy. The other half felt that you could become digitally literate without being literate. We knew answers and theories would emerge from our research.

\section{Procedures and Methods}

The first author served as recruiter and logistician. He found 3 team members from a company volunteer program and 7 more local Indian team members through his networks. At the same time, he recruited communities to serve as field locations for research (Table II).

\begin{tabular}{|c|c|}
\hline Name & Description \\
\hline Aware & $\begin{array}{l}\text { Welfare, health, and nutrition community focusing on naturopathy in } \\
\text { Delhi }\end{array}$ \\
\hline$\underline{\text { Just Flowers }}$ & $\begin{array}{l}\text { Two Delhi locations of a flower shop chain including mostly females } \\
\text { who work in the flower shop, male delivery workers, and mixed } \\
\text { office workers }\end{array}$ \\
\hline $\begin{array}{l}\text { Helping Women Get Online } \\
(\mathrm{HWGO})\end{array}$ & Helpline agents based in Delhi \\
\hline $\begin{array}{l}\text { Male drivers for a technology } \\
\text { company }\end{array}$ & Delhi \\
\hline Salaam Baalak Trust Arushi & $\begin{array}{l}\text { Delhi children's home for girls; meeting with girls and staff } \\
\text { members }\end{array}$ \\
\hline Vidya and Child & $\begin{array}{l}\text { Delhi children's program and school for boys and girls; meeting with } \\
\text { children and staff }\end{array}$ \\
\hline $\begin{array}{l}\text { READ Alliance project in care } \\
\text { of Center for Knowledge } \\
\text { Societies (CKS) }\end{array}$ & $\begin{array}{l}\text { USAID-funded early-childhood reading and literacy program } \\
\text { managed throughout India by CKS in Delhi; meeting with READ } \\
\text { Alliance program managers and CKS CEO }\end{array}$ \\
\hline$\underline{\text { Nakul }}$ & $\begin{array}{l}\text { Agency lead for HWGO's ground activations in northern states of } \\
\text { India }\end{array}$ \\
\hline Neela Kaushik & $\begin{array}{l}\text { Wife, mother, and entrepreneur who started a website to help } \\
\text { connect mothers in Gurgaon }\end{array}$ \\
\hline
\end{tabular}




\begin{tabular}{|c|c|}
\hline $\begin{array}{l}\text { Self-employed Women's } \\
\underline{\text { Association (SEWA) }}\end{array}$ & $\begin{array}{l}\text { Delhi community of low-income, mostly Muslim women working to } \\
\text { improve their lives; meeting with women and staff }\end{array}$ \\
\hline $\begin{array}{l}\text { Network for Information and } \\
\text { Computer Technology (NICT) } \\
\text { in Indore }\end{array}$ & $\begin{array}{l}\text { Meetings with } \mathrm{CEO}, \mathrm{COO}, \mathrm{CTO} \text {, project lead, director, and district } \\
\text { manager }\end{array}$ \\
\hline $\begin{array}{l}\text { Visits to Common Service } \\
\text { Centers (CSCs) in and around } \\
\text { Indore }\end{array}$ & $\begin{array}{l}\text { Urban, peri-urban, and rural CLC visits outside of Indore; CLCs are } \\
\text { tele-centres offering many government services and trainings } \\
\text { through technology }\end{array}$ \\
\hline $\begin{array}{l}\text { Visit to rural and peri-urban } \\
\text { CSC in Kalcheena }\end{array}$ & $\begin{array}{l}\text { Outside Ghaziabad and Meerut; meeting with Village Level } \\
\text { Entrepreneur (VLE) Mr. Akbar Ali and adults and children involved } \\
\text { in community and learning classes; Mr. Akbar Ali is the VLE of the } \\
\text { CSC in Kalcheena }\end{array}$ \\
\hline $\begin{array}{l}\text { Delhi India Linux User Group } \\
\text { (ILUG) at Jawaharlal Nehru } \\
\underline{\text { University }}\end{array}$ & Professors, researchers, graduate and undergraduate students \\
\hline $\begin{array}{l}\text { Urban, informal settlement } \\
\text { observation }\end{array}$ & Gurgaon \\
\hline$\underline{\text { Hole-in-the-Wall location in }}$ & Meeting with children, manager, and regional manager \\
\hline
\end{tabular}

The entire team met in Delhi to prepare. First digital literacy was defined generally. Then the team defined the design challenge, constraints and preferences.

Design a low-cost, portable, updatable, easily set-up, time-flexible, understandable solution for the digitally illiterate in Delhi, enabling them to use digital technology, reducing the digital divide.

- Constraints

○ Time flexible

- Portable

- Low-cost

- Beneficial

- Updatable

- Easily set-up

- Understandable 


\section{- Preferences}
○ Short
$\circ$ Engaging/Interesting
- Globally accessible
- Accessible to differently-abled

The constraints, built into the design challenge, are characteristics of the solution that are required for it to work. The preferences are desired characteristics of the solution without which, the solution still works.

Next, all the following research methods were chosen and later employed.

- Individual interview - an interview with only one interviewed person

- Group interview - an interview in which questions are posted to a group and group members take turn individually answering

- Expert interview - an interview with someone who has a relevant expertise, in this case, technology, digital literacy, education, etc.

- Observation - a period of watching and documenting learners or users in their natural environment without interpreting what is happening

- In context immersion - the act of meeting people where they live, work, or socialize and experiencing life with them including working alongside them, homestays, etc.

- Community-driven discovery - co-participatory research in which the people for whom you are designing are also members of your design and research teams

Next, for the individual, expert, and group interviews, we chose a semi-structured interview approach, developed an interview guide, and then prepared and practiced interviewing other research teammates. The preparation included training for bias awareness (discussing our previous experiences and backgrounds and how they affect our views), bias journaling (journaling about all the biases we bring to this work related to India, education, digital tools, etc.), observing versus interpreting (differentiating between objective observation [what we see] versus subjective documentation [what we infer or the effect of the lens through which we see]), and other interview techniques. These trainings were done in order to lessen the influence of our bias, biased interpretations, and preconceived notions of what we thought people needed or wanted. We wanted to let the qualitative data speak on its own.

We then broke into smaller teams of 3 and conducted our interviews and observations throughout north and central India. We reconvened and conducted a knowledge inventory, a collaborative exercise to answer the following four questions.

1. What do people need or want?

2. What technologies can help with this challenge?

3. What solutions or ideas are being tried in other areas?

4. What early hypotheses do you have about how to solve this design challenge?

One purpose of such a knowledge inventory is to uncover tensions between what different team members think or found. For example, this exercise revealed tensions between those who thought an online solution was sufficient versus those who favored an offline or hybrid solution. 
We also found that some team members thought only highly localized solutions could work while others thought one global solution would suffice.

The main purpose of a knowledge inventory is to uncover strengths and weaknesses that direct further research. Out of the 4 questions, the team's strength was in understanding the educational landscape of India and understanding people's wants and needs. The team's weakness were in understanding the cultural value of IT in India, purchasing power of various groups, government offerings in the area of digital literacy, as well as other solutions whether successful or unsuccessful.

Finally, we paused to reconsider the challenge. Often after conducting initial discovery research, we find that the the challenge is not actually a problem among those observed and interviewed. Or we may find the problem is too broad or too narrow. However, in this case, all team members agreed: our qualitative research confirmed the design challenge, so it was not changed.

In the next section, we conduct synthesis, code the stories and qualitatively analyze data to extract insights and find themes. Through further analysis we unearth frameworks as learning theories emerge.

\section{SYNTHESIS}

\section{Themes and Insights}

Key insights grouped by themes are seen in Table III. First, the research team deconstructed all qualitative data into single-idea, individual quotes, facts, and observations. Then the research team connected various quotes, facts, and observations to extract hidden insights (right column of Table III) not directly captured in a quote, fact, or observation. The research team then grouped all insights, facts, quotes, and observations into broad categories or themes. We regrouped and regrouped the themes until we felt the final themes were on the same high level, spoke about similar things, and captured the emerging patterns in the data. Excluding gender, all other themes appeared in every single interview or observation. Gender emerged in $95 \%$ of the interviews and observations. The final high-level themes are in the left column of Table III. Because insights do not capture all of the data (facts, quotes, observations), it is important to highlight crucial points.

First, a curriculum based on a local definition of digital literacy must relate to education, transportation, power, health, and government accountability--the areas of need for which 95\% of community members, in our research locations, want help. No one was interested in general digital literacy, not even experts. Donor agencies, institutions, and governments were interested in digital literacy for literacy volunteerism or youth workforce development. ${ }^{50}$

Second, both existing technology and infrastructure themes relate to access. Most people focus on Internet access, but access also includes energy access as well as device access. 
TABLE III

INSIGHTS GROUPED BY THEMES

\begin{tabular}{|c|c|}
\hline Themes & Insights \\
\hline $\begin{array}{l}\text { Existing } \\
\text { Technology }\end{array}$ & $\begin{array}{l}\text { Youth are heavily engaged in social media. } \\
\text { Internet is viewed as a more modern advanced version of TV. }\end{array}$ \\
\hline Infrastructure & $\begin{array}{l}\text { Growing up in a physically unhealthy environment impairs learning ability. } \\
\text { Poor health or disease is a barrier for education. } \\
\text { Lack of access \& infrastructure are barriers to digital literacy. }\end{array}$ \\
\hline What to teach & $\begin{array}{l}\text { People are lacking proper evaluation skills. } \\
\text { People are willing to learn by talking and not by reading. } \\
\text { English language is correlated to ICT use and can be a barrier and facilitator. }\end{array}$ \\
\hline How to teach & $\begin{array}{l}\text { Learners prefer education that is fun. } \\
\text { Education that engages in analysis has a bigger, long-term impact than focusing on } \\
\text { remembering, understanding, and applying. } \\
\text { Illiteracy rates are high and those with low literacy are aided by pictures, images, } \\
\text { and video. } \\
\text { Kids sometimes teach ICT to adults. }\end{array}$ \\
\hline Gender & $\begin{array}{l}\text { Some men do not allow women to work. } \\
\text { Less women are given access to Internet. } \\
\text { Women are strongly concerned with safety (unwilling to leave comfortable zones } \\
\text { to learn). } \\
\text { In the most successful social programs, girls and women are addressed specifically. }\end{array}$ \\
\hline Money & $\begin{array}{l}\text { Choice of phone is strongly dependent on purchasing power. } \\
\text { People are money conscious. } \\
\text { Pricing of digital literacy solutions strongly impact participation. }\end{array}$ \\
\hline Motivation & $\begin{array}{l}\text { Parents are willing to spend money if it is beneficial to kids. } \\
\text { Movie stars are symbols on the level of God so they are used to reach people. } \\
\text { People will learn if it fulfills an immediate need. } \\
\text { The elderly hesitate to engage in new technologies and rely on children and } \\
\text { grandchildren to use such tools. } \\
\text { People will adopt ICT if it helps to elevate socioeconomic status. } \\
\text { People are unaware of government provisions. } \\
\text { Happiness can be increased with one's ability to make money. }\end{array}$ \\
\hline
\end{tabular}

Gender also emerged as an access issue. In India, women have less access to the Internet than men. Not only do some men control access for women (more so in rural areas), a lack of safety dissuades women from using Internet cafes which are dominated by men. This was mentioned by $100 \%$ of women interviewed in urban, peri-urban, and semi-rural areas. 
Money and motivation are also barriers to access. In many areas in India, smart phones are not the norm. So any digital literacy solution will have to involve feature phones and basic phones permitting SMS-based ways of accessing information. However, even people with little money are willing to spend money if it will improve the lives of their children.

Additionally, both China and India have majority rural populations. In order to bring the next 4 billion online, the solution must involve rural people which automatically means it must involve local languages outside of English, inasmuch as there is an Internet presence for a local language. Moreover, reading-writing literacy is a huge barrier, and any digital literacy must address the problem.

Finally, access and training outside of any digital literacy education classroom is important for practice.

\section{Frameworks and Learning Theories}

Our research reveals relationships that help settle aforementioned learning theory debates. First, based on our communities, we believe considerable numbers of people cannot become digitally literate on their own. The closest counterexample we found is one example of a few adult women learning some digital literacy at a Hole-in-the-Wall location (see Table II). However, it's important to note, Hole-in-the-Wall is not self-learning, it is a Self-organized Learning Environment (SOLE) ${ }^{51}$. In a SOLE, students learns through a group of peers.

Our second theory is that MOOCs are not sufficient to scale digital literacy education. Effective education depends on both the content and the delivery. Having great content and poor delivery means poor results and little change. The most impacting factor for student success is teacher excellence ${ }^{52}$. Even a poor teacher with really good curriculum can produce poor results. We learned that no matter the quality of what is produced, if a teacher is involved, so much depends on the quality, skills, and emotional intelligence of that teacher. If you remove the teacher from the delivery model, the most impacting factor changes. In a SOLE, the learner group becomes the teacher. With self-learning, the student and teacher are one. This shows why it is so difficult for people completely new to the Internet to learn to use the Internet alone through a MOOC. It is difficult to teach yourself how to use the Internet by using the Internet if you are completely new to the Internet or computers. If you're using a MOOC, you most likely know how to use a web browser, and you know how to search. We saw no evidence of those who were not digitally literate using MOOCs. MOOCs were used by the more educated, English speakers of higher income levels.

Our third theory is that, for a given amount of training hours, mastery and retention are higher if the entire training is done directly through the device, rather than splitting the training between an offline classroom time and an online device interaction lab. This comes from our observations of the speed of learning when interacting with a device.

Fourth, we theorize that bringing the next 4 billion online will require multiple local solutions. From our insights we saw that communities were more interested in contextualized learning relevant to their lives. Since problems, issues, ambitions and hopes vary around the world, the contextualization and, hence, the curriculum, will also vary.

Finally, we believe digital literacy does require reading-writing literacy as our insights uncover. Although it is possible to do minimal actions online like click YouTube videos without 
being able to read the titles, the internet is so dominantly text-based that it requires a certain level of reading-writing literacy to navigate and evaluate the page. Text-to-speech apps are not prevalent enough to eliminate this requirement. Therefore bringing the next 4 billion online implies three options due to huge literacy barriers. Either ignore the reading-writing illiterate and only teach digital literacy to those who are reading-writing literate in a particular language limiting your learner pool and failing to reach the next 4 billion. Or build reading-writing literacy into a digital literacy solution widening the solution and handling the problem directly. Or partner with reading-writing literacy organizations so that partner efforts feed newly literate people into your digital literacy efforts so all can benefit from the digital literacy training. As we move forward in designing a solution, we must choose one option. This leads us to the following relational framework that arose out of our research.

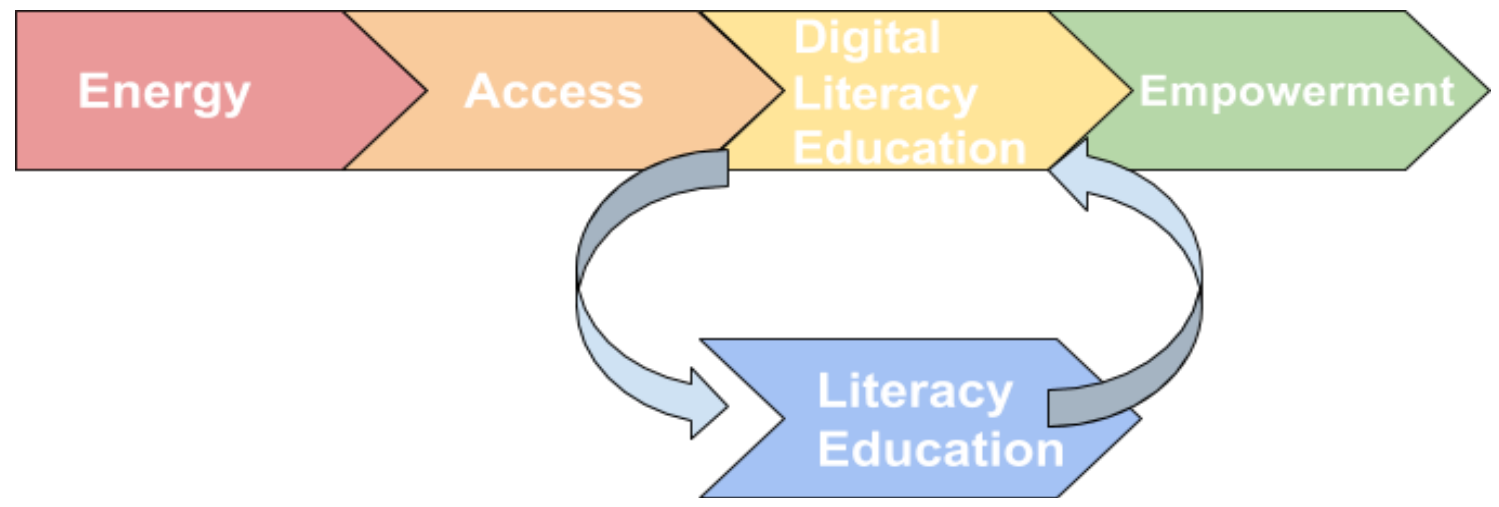

FIGURE I

The Connection between Energy, Access, Literacy, and Digital Literacy Education

In our research communities, there are people who are digitally illiterate due to energy insecurity. Others have consistent energy, but lack consistent Internet access and device access. Once someone has consistent energy, Internet, and device access, digital literacy is possible if they are already reading-writing literate in a language with substantial presence on the Internet. We discovered that literacy education could then lead to digital literacy education. What surprised us is that digital literacy education could lead to literacy education through the mechanism of literacy programs. There are programs that focus on digital literacy for literacy volunteerism; in other words, people are trained to become digitally literate and then use those computer and Internet skills to teach people to read using computer and phone applications ${ }^{52}$. This is why Figure 1 shows the revolving relationship between literacy and digital literacy education.

The final framework we created was a theory of change and root cause analysis of why the global proliferation of Web Academy courses has been failing (a negligible number of certifications had been recorded globally). Web Academy partnered with Telecentre Foundation (TCF), a global network of tele-centres (internet cafes with classes and government services) but only at an international level, and few people were being trained through this partnership ${ }^{53}$. Our research included interviews with Indian village level entrepreneurs (VLEs) who run tele-centres called local community service centers (CSC), district managers, regional managers, and the 
regional headquarters for CSCs in India. We uncovered that local CSCs can and do deliver education but their delivery model is different than that prescribed by our international partnership model of free classes.

The problems were three-fold. First the VLEs made no money for teaching Web Academy courses which were supposed to be offered for free, therefore they had no incentives to teach them. Second, the TCF had very little control over what happened on the ground in local telecentres around the world. Lastly, in India, many of the CSCs simply did not have the space or equipment to run the trainings required by TCF. We recommend three changes in order to help the Web Academy materials spread around the world. These recommendations will inform our design as we move forward:

1. Work with CSCs at a regional level, not international: the more control over individual CSCs your partner has the better.

2. Design a revenue-generating model for the VLEs who educate people. This is the exact model for all the other services VLEs offer, from government e-services and mobile banking to telemedicine and stocks.

3. Support tele-centres with infrastructure and space to increase their capacity and ability to run educational trainings: Most CSCs we saw did not have the space or equipment to do trainings. They primarily focused on services. Some offered trainings, but to scale up, they need more equipment, better access, and more space.

\section{Design Principles}

TABLE IV

DESIGN PRINCIPLES

\begin{tabular}{|c|l|}
\hline Number & \\
\hline 1 & Design for mobile. \\
\hline 2 & Separate mobile-based and computer-based modules. \\
\hline 3 & Make it highly visual. \\
\hline 4 & Make it auditory. \\
\hline 5 & Include local languages. \\
\hline 6 & Contextualize in relevant problems. \\
\hline 7 & Make it modular with rapid assessments. \\
\hline 8 & Design for skills. \\
\hline 9 & Design device-based instruction. \\
\hline 10 & Teach learners on the device thev will use. \\
\hline 11 & Integrate Internet Safetv throughout the curriculum. \\
\hline 12 & Include certification. \\
\hline 13 & Prioritize touchscreen interactions. \\
\hline
\end{tabular}


As a final step, we translated our findings, theories, and insights into design principles that guide our work forward (Table IV). The thirteen principles are not in order of importance.

Principles 1 and 2 dictate our solution should work for mobile phones as well as conventional computers. It should include feature-phone and basic-phone education as well. This means including locally relevant SMS-based services that show how ICT is used to help meet locally relevant problems, issues, and needs. However, the modules for mobile phone digital literacy and computer education should be separate rather than integrated to allow for personalization. Some learners are only interested in one.

Principles 3-5 increase access to our digital literacy solution. It should at least be offered in local languages with which one can search the Internet.

Principles 6-10 will help increase mastery and retention. Learning grounded in the problems of everyday life is helpful. Modularity and rapid assessments increase access, flexibility, feedback, and personalization. Skills-based assessments are more appropriate since the purpose is to equip people with skills. Retention is higher when people learn on the actual device instead of learning in a classroom apart from the device and later going to a lab where they work on the device. Moreover, they should learn on the actual device they will use in life. We did see examples of people who learned to use computers through in-class practice alone and then later found jobs working on computers at a local G2C (Government to Community centre, similar services as CSC). However, if someone has a device at home, work, or school, sometimes they struggle with doing the same things if it is tried on a different machine. This is especially true with different phone types and operating systems.

Though mobile and computer education are separated for personalization, everyone needs to learn about Internet safety. We recommend, therefore, that Internet safety is integrated throughout according to Principle 11.

Principle 12 is a design for motivation. In emerging market countries, certifications are quite important and crucial for finding a job. In fact, it is not enough to gain a certification. In India, job seekers actually print out paper copies of the certification and bring it into the interview.

Principle 13 reflects the fact that India has already reached the point where smartphone purchases outnumber other types of phone purchases. This doesn't meant that smartphones are the majority phone, yet. But it does mean that touch-based applications are becoming more used. To deal with the tension, we suggest a curriculum that includes some touchscreen practice.

Lastly, though not a primary design principle, we offer another principle to guide future partnerships with TCF. Start small. Test and prove the model, then scale to other CSCs and telecentres. This is the opposite of what was done through our international partnership.

\section{Conclusion}

In this work, we presented the use of a human-centered design methodology to guide the designbased implementation research process, creating a contextualized definition of digital literacy for central and Northern India and redesigning our digital literacy curriculum. Since instructional design includes not just the design of the content, but also the delivery of the content, our design research also aimed to uncover weaknesses in our international delivery model used to bring the next 4 billion online. 
We find that any definition of digital literacy must include how people can use ICT to solve health, transportation, energy, educational, and government accountability problems in north and central India. The specific tasks and actions will emerge as we continue the design process in the future.

The most important high-level themes that emerge from our work are infrastructure, existing technology, money, gender, content, pedagogy, and motivation. The most important are those that act as a barrier to access, specifically money, gender, motivation, infrastructure, and existing technology.

The most important framework we find connects energy, devices, Internet, and literacy. People first need energy access. With consistent access some people still lack Internet access. With consistent Internet access, one still needs device access. Once all three are in place, digital literacy is possible and can lead to greater social and economic empowerment. Additionally, we find that reading-writing literacy can function as a stepping stone to digital literacy, and paradoxically digital literacy can lead to increased literacy. This happens through "digital literacy for youth workforce development" or "digital literacy for literacy volunteerism" programs which help the newly digitally literate work and volunteer in roles that use computer applications to teach others to read.

Throughout the research process, several learning theories emerge. First, reading-writing literacy is a requirement for digital literacy due to the nature of the Internet today. Second, significant numbers of people cannot become digitally literate on their own. Third, MOOCs are an ineffective way to teach people, who are not digitally literate, to become digitally literate. Digital literacy requires a high-touch method that cannot be avoided. Fourth, mastery and retention are higher when learners learn directly on a connected device rather than in a classroom on paper and then later in a lab using the device. Last, helping the next 4 billion online will require multiple local solutions, not one global solution.

Our research also uncovered weaknesses in our current distribution model to deliver our digital literacy solution globally through Telecentre Foundation (TCF). First, TCF has no direct control over local tele-centres. In the India tele-centres (CSCs), the local VLEs had no monetary incentive to teach the course. Finally many, CSCs had inadequate equipment and space to teach our digital literacy curriculum. Our recommendation is to start future partnerships on a small scale and prove the model first before scaling.

All insights and qualitative data have been synthesized and translated into thirteen design principles. These design principles will guide the next phase of our work in which we begin to identify opportunity areas, ideate, brainstorm, prototype and gather feedback on prototypes from future community research visits. We will iterate and improve those prototypes until they reach an acceptable level with our communities before we move into the final delivery stage in which we focus on piloting an early-stage version of the solution.

\section{ACKnow Ledgements}

The authors would like to thank Fiona, Natasha, the Web Academy team and 20\% volunteers (company workers who donate 1 day a week or $20 \%$ of work time to help Web Academy), as well as the Reach program managers, ambassadors, volunteers, and all community groups who participated. 
International Journal for Service Learning in Engineering,

Humanitarian Engineering and Social Entrepreneurship

Vol. 11, No. 2, pp. 18-37, Fall 2016

ISSN 1555-9033

\section{REFERENCES}

1 "Overview: Strengthening the Analog Foundation of the Digital Revolution." World Development Report 2016: Digital Dividends, January 14, 2016, 1-41. Accessed April 12, 2016. doi:10.1596/9781-4648-0671-1_ov.

2 Pham, Thi Luc Hoa, ICT Development Strategies, (Hamburg: Anchor Academic Publishing, 2014), $81 \mathrm{ff}$.

3 Hunsinger, Jeremy, Lisbeth Klastrup, and Matthew Allen, eds. The International Handbook of Internet Research, (Dordrecht: Springer, 2010), 203.

4 Amiri, Shahram and Brian Reif, "Internet Penetration and its Correlation to Gross Domestic Product: An Analysis of the Nordic Countries," International Journal of Business, Humanities and Technology 3, no. 2 (2013) 50-60.

5 Sprague, Kara, James Manyika, Bertil Chappuis, Jacques Bughin, Ferry Grijpink, Lohini Moodley, and Kanaka Pattabiraman. Offline and falling behind: Barriers to Internet adoption, (San Francisco: McKinsey, 2014) $13 \mathrm{ff}$.

6 Katz, Raul. The Impact of Broadband on the Economy: Research to Date and Policy Issues. Geneva: ITU, 2012. Accessed April 8, 2016. https://www.itu.int/ITU-D/treg/broadband/ITU-BB-

Reports Impact-of-Broadband-on-the-Economy.pdf.

7 du Rausas, Matthieu Pélissié, James Manyika, Eric Hazan, Jacques Bughin, Michael Chui, and Rémi Said. Net's sweeping impact on growth, jobs, and prosperity. New York: McKinsey, 2011. Accessed April 8, 2016. http://www.mckinsey.com/industries/high-tech/our-insights/internet-matters.

8 Sprague et al. Offline and falling behind: Barriers to Internet adoption, $30 \mathrm{ff}$.

$9 \quad$ Sprague et al. Offline and falling behind: Barriers to Internet adoption, 8.

10 Cook, James. "This Is The \$33 Smartphone For India That Could Ruin Samsung's Android Business." Business Insider. 2014. Accessed April 08, 2016. http://www.businessinsider.com/mozilla-33-intexcloud-fx-smartphone-in-india-2014-8.

11 Brahima Sanou, Foreword to Measuring the Information Society Report 2013 by ITU (Geneva: International Telecommunications Union 2014) iii.

12 Brahima Sanou, Foreword to Measuring the Information Society Report 2014 by ITU (Geneva: International Telecommunications Union 2015) iii-iv.

13 Brahima Sanou, Foreword to Measuring the Information Society Report 2015 by ITU (Geneva: International Telecommunications Union 2016) 2.

14 Brahima Sanou, foreword, iii.

15 Brahima Sanou, foreword, 249.

16 Tinder Foundation. Accessed April 09, 2016. http://www.tinderfoundation.org/

17 McDonald, Catherine. A Leading Digital Nation by 2020: Calculating the cost of delivering online skills for all. London: Tinder Foundation \& Go On UK, 2014. Accessed April 9, 2016.

https://www.tinderfoundation.org/sites/default/files/researchpublications/a_leading_digital_nation_by_2020_0.pdf.

18 Web Academy Online Basics curriculum. Accessed April 09, 2016 https://drive.google.com/drive/u/0/folders/0BxQkc5KBA9IlV1YybG5ja01COWM.

19 Dabla-Norris, Era, Kalpana Kochhar, Nujin Suphaphiphat, Frantisek Ricka, and Evridiki Tsounta. "Causes and Consequences of Income Inequality: A Global Perspective." IMF Staff Discussion Notes 15, no. 13 (June 2015): 4, 10ff. doi:10.5089/9781513555188.006.

20 Chusseau, Nathalie, and Joël Hellier. "Inequality in Emerging Countries." SSRN Electronic Journal SSRN Journal. doi:10.2139/ssrn.2131360.

21 "Chapter 3. Inequality and Economic Mobility." Economies of Emerging Markets Better Rated During Difficult Times. Pew Research Centers Global Attitudes Project RSS. May 23, 2013. 
International Journal for Service Learning in Engineering,

Humanitarian Engineering and Social Entrepreneurship

Vol. 11, No. 2, pp. 18-37, Fall 2016

ISSN 1555-9033

Accessed April 10, 2016. http://www.pewglobal.org/2013/05/23/chapter-3-inequality-and-economicmobility/.

22 "Special Focus: Inequality in Emerging Economies (EEs)." In Divided We Stand Why Inequality Keeps Rising. Paris: OECD, 2011. Accessed April 10, 2016.

https://www.oecd.org/els/soc/49170475.pdf.

23 Vieira, Sergio. Inequality on the Rise? An Assessment of Current Available Data on Income

Inequality, at Global, International and National Levels. Report. December 2012. Accessed April 10, 2016.

http://www.un.org/en/development/desa/policy/wess/wess_bg_papers/bp_wess2013_svieira1.pdf.

24 "Implications of Rising Inequality in Emerging Markets." Carnegie Endowment for International

Peace. November 17, 2011. Accessed April 10, 2016.

http://carnegieendowment.org/2011/11/17/implications-of-rising-inequality-in-emerging-markets.

25 "Digital Literacy Definition and Resources." Digital Literacy Definition and Resources. October 15, 2008. Accessed April 11, 2016. http://www.library.illinois.edu/diglit/definition.html.

26 "Enhancing Digital Literacy." What Is Digital Literacy? 2016. Accessed April 11, 2016. http://schools.nyc.gov/community/innovation/ConnectedFoundations/EDL/default.htm.

27 "ECDL Foundation." ECDL Foundation. 2015. Accessed April 11, 2016. http://www.ecdl.org/index.jsp?p=826.

28 Anderman, Eric. "Research Methods: An Overview." Research Methods: An Overview. December 23, 2009. Accessed April 11, 2016. http://www.education.com/reference/article/research-methods-anoverview/.

29 "Explanation - What Is Design-Based Research (DBR)?" Explanation - What Is Design-Based Research (DBR)? 2006. Accessed April 11, 2016. http://dbr.coe.uga.edu/explain01.htm.

30 "Design-Based Research: An Emerging Paradigm for Educational Inquiry." Educational Researcher 32, no. 1 (2003): 5-8. Accessed April 11, 2016. doi:10.3102/0013189x032001005.

31 Tatar, Deborah. "The design tensions framework." Human-Computer Interaction 22, no. 4 (2007): 413-451.

32 Penuel, William R. "Infrastructuring As a Practice for Promoting Transformation and Equity in Design-Based Implementation Research." (2015).

33 Penuel, William R., and Angela Haydel DeBarger. "A Research-Practice Partnership to Improve Formative Assessment in Science."

34 Roschelle, Jeremy, Jennifer Knudsen, and Stephen Hegedus. "From new technological infrastructures to curricular activity systems: Advanced designs for teaching and learning." In Designs for learning environments of the future, pp. 233-262. Springer US, 2010.

35 Coburn, Cynthia E., Jennifer L. Russell, Julia Heath Kaufman, and Mary Kay Stein. "Supporting sustainability: Teachers' advice networks and ambitious instructional reform." American Journal of Education 119, no. 1 (2012): 137-182.

36 Sabelli, Nora, and Chris Dede. "Empowering Design-Based Implementation Research: The Need for Infrastructure."

37 "Design Based Implementation Research." DBIR $\rightarrow$ Principles. 2016. Accessed April 11, 2016. http://learndbir.org/principles.

38 Jacobson, Robert, ed. "Chapter 4: Human-centered Design." In Information Design, by Mike Cooley, 59-81. Cambridge: MIT Press, 2000.

39 IDEO.org. HCD Toolkit. San Francisco: IDEO.org, 2013. 2nd edition.

40 IDEO.org. The Field Guide to Human-centered Design. San Francisco: IDEO.org, 2015. 1st edition.

41 Friedman, Batya, and David Hendry. "The envisioning cards: a toolkit for catalyzing humanistic and technical imaginations." In Proceedings of the SIGCHI conference on human factors in computing systems, pp. 1145-1148. ACM, 2012. 
International Journal for Service Learning in Engineering,

Humanitarian Engineering and Social Entrepreneurship

Vol. 11, No. 2, pp. 18-37, Fall 2016

ISSN 1555-9033

42 Simonsen, Jesper, and Finn Kensing. "Using ethnography in contextual design." Communications of the ACM 40, no. 7 (1997): 82-88.

43 Millen, David R. "Rapid ethnography: time deepening strategies for HCI field research." In Proceedings of the 3rd conference on Designing interactive systems: processes, practices, methods, and techniques, pp. 280-286. ACM, 2000.

44 Barab, Sasha A., Michael K. Thomas, Tyler Dodge, Kurt Squire, and Markeda Newell. "Critical design ethnography: Designing for change." Anthropology \& Education Quarterly 35, no. 2 (2004): 254-268.

45 Bang, Megan, Douglas Medin, Karen Washinawatok, and Shannon Chapman. "Innovations in culturally based science education through partnerships and community." In New Science of Learning, pp. 569-592. Springer New York, 2010.

46 Penuel, William R., Samuel Severance, Raymond Johnson, Heather Leary, and Susan Miller. "The Emergence of New Objects in Co-Design: A Cultural-Historical Activity Theoretical Analysis." Proceedings of the 11th International Conference of the Learning Sciences, June 2014. Accessed April 12, 2016. http://learndbir.org/resources/Negotiating_the_Object_in_CoDesign.pdf.

47 Muller, Michael J., Daniel M. Wildman, and Ellen A. White. "Taxonomy of Participatory Design Practices." Posters and Short Talks of the 1992 SIGCHI Conference on Human Factors in Computing Systems - CHI '92, 1992. Accessed April 12, 2016. doi:10.1145/1125021.1125053.

48 Muller, Grudin, Jonathan, and John Pruitt. "Personas, participatory design and product development: An infrastructure for engagement." In PDC, pp. 144-152. 2002.

49 "Influential Theories of Learning | Education | United Nations Educational, Scientific and Cultural Organization." Influential Theories of Learning | Education | United Nations Educational, Scientific and Cultural Organization. 2016. Accessed April 22, 2016. http://www.unesco.org/new/en/education/themes/strengthening-education-systems/qualityframework/technical-notes/influential-theories-of-learning/.

50 Leege, Rebecca. "All Children Reading Grand Challenge for Development." January 30, 2014. Accessed April 27, 2016. http://pdf.usaid.gov/pdf docs/PA00JNFJ.pdf.

51 Mitra, Sugata. Beyond the Hole in the Wall. TED Books, 2012.

52 Boothe, Diane. "What Matters Most: Teaching for America's Future." A Review. Current Issues in Middle Level Education 6, no. 1 (1997): 88-92.

53 Telecentre Foundation. 2016. Accessed May 30, 2016. http://www.telecentre.org/. 